\title{
Gentes e paisagens do Rio Iguaçu na viagem expedicionária dos engenheiros Keller em $1866^{1}$
}

\section{The peoples and the landscapes of the Iguaçu River on the expedition of the Keller engineers in 1886}

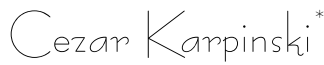

\section{Introdução}

Desde a emancipação da Província do Paraná em dezembro de 1853, os governantes nutriram, em seus discursos, a necessidade de conhecer o rio Iguaçu a fim de nele estabelecer uma navegação que facilitasse a ocupação dos territórios por ele percorridos. Incluso nesta perspectiva, estava o desejo de mapear os recursos naturais para a colonização e ocupar os espaços considerados "vazios" ou "despovoados" das regiões oeste e sudoeste paranaenses. Atendendo a estes anseios, várias ações se voltaram para este fim entre os anos de 1853 e 1866, quando determinados personagens embarcaram em canoas e se lançaram em suas águas. Geralmente saíam das proximidades de Curitiba com a missão de navegar até onde fosse possível, fazendo medições, descrevendo acidentes geográficos e mapeando o percurso do rio. Essas viagens foram, quase sempre, documentadas e alguns diários foram publicados em jornais da época ou constam nos relatórios dos presidentes da Província. ${ }^{2}$

\footnotetext{
${ }^{1}$ Este artigo é resultado de algumas discussões presentes em: KARPINSKI, Cezar. Navegação, cataratas e hidrelétricas: discursos e representações sobre o rio Iguaçu (Paraná, 18531969). 2011. 395f. Tese (Doutorado em História). Universidade Federal de Santa Catarina, Florianópolis, 2011. Orientador: Marcos Fábio Freire Montysuma.

* Doutor em História Cultural pela Universidade Federal de Santa Catarina (UFSC), Professor do Departamento de História da Universidade Federal de Integração Latino-América (UNILA).E-mail: cezark@hotmail.com

${ }^{2}$ Para o levantamento historiográfico e discussões acerca do contexto histórico destas
} 
Dentre estas viagens, considero a mais significativa ados engenheiros Joseph e Franz Keller ou "José e Francisco" Keller, como traduziram os documentos da época, realizada em 1866. Considerada uma "expedição", a passagem destes personagens pelo rio Iguaçu e o relatório por eles produzido possibilitam analisar como se construíram e foram se nutrindo, ao longo do tempo, os discursos em torno do aproveitamento dos recursos naturais da região banhada por este rio. Além disso, o discurso presente no extrato da expedição constitui um tipo de paisagem que insere elementos de identidade regional e relações sociais que ultrapassavam os limites do rio.

Neste sentido, analiso como as descrições sobre o rio Iguaçu e suas características contribuem para as discussões historiográficas sobre a região. Para tanto, utilizo, além do documento produzido na expedição, algumas discussões e críticas de autores que buscaram historiar a ocupação regional a partir do elemento "natural" rio Iguaçu, principalmente o que se convencionou chamar de "Região do Médio Vale do Iguaçu" ou "Região do Médio Iguaçu", onde se instalaram cidades como São Mateus e União da Vitória.

É importante ressaltar que a expedição ao rio Iguaçu fez parte de um projeto imperial que buscava conhecer os rios brasileiros que, de alguma forma, possibilitassem ligações com a provincia do Mato Grosso no contexto da Guerra do Paraguai. Para tanto, os Keller percorreram os rios Ivaí, Tibagi e Paranapanema (norte da Província do Paraná) e posteriormente o Iguaçu, sempre apontando possibilidades ou inviabilidades de trajetos navegáveis que levassem à Província de Mato Grosso. As autorizações governamentais por parte da Provincia do Paraná foram concedidas em dezembro 1864, data em que se inicia a ofensiva paraguaia para ocupação de terras mato-grossenses. ${ }^{3}$

Segundo Romário Martins, "ao irromper a guerra com o Paraguai o governo imperial promoveu a exploração dos grandes rios da Província do Paraná que pudessem servir de comunicação com a Província do Mato Grosso: o Ivaí, o Tibagi

viagens e expedições cf. KARPINSKI, op.cit., p.21-44.

${ }^{3}$ BETHEL, Leslie. Cronologia da Guerra. In. MARQUES, Maria Eduarda Castro Magalhães (Org.). A Guerra do Paraguai: 130 anos depois. Rio de Janeiro: Relume-Dumará, 1995, p.32. 
e o Paranapanema". ${ }^{4}$ Sendo assim, as expedições daqueles rios balizaram as experiências e as diretrizes para a expedição ao Iguaçu, iniciada em $1866 .{ }^{5}$ Este contexto histórico daGuerra do Paraguai e do início doParaná como Província independe fazdo relatório dosKeller um documento importante para as discussões históricas do Paraná oitocentista, bem como as interconexões com a história regional.

\section{Os engenheiros Keller e a "grande expedição" de 1866}

Pelo que se percebe nas fontes e na historiografia em geral, José e Francisco Keller, sob as ordens do governo imperial, realizaram vários estudos com o intuito de viabilizar algumas vias de comunicação no Brasil do Século XIX. Segundo Cândido Mello-Leitão, as expedições destes engenheiros não se enquadram no que se convencionou chamar "Grandes Expedições Científicas do Século XIX", mesmo assim, pelos levantamentos geográficos que elaboraram, têm grande importância no cenário científico do Brasil oitocentista. Para Mello-Leitão, as expedições dos Keller são denominadas, na história das expedições científicas, de "expedições científicas menores, com caráter geográfico". ${ }^{6}$

Diplomados pela Escola Técnica de Carlsburg - Alemanha, José e Francisco Keller foram contratados pelo Governo Imperial em 1853, ano provável de sua chegada ao Rio de Janeiro. Segundo Maria Nicolas, foram agregados ao Ministério de Agricultura e iniciaram seus trabalhos com o levantamento dos rios Paraíba e Pombo, o que se tornaria a principal atividade destes engenheiros no Brasil, onde permaneceram até $1873 .{ }^{7}$ A utilização de métodos e técnicas diferenciadas fez com que os estudos dos Keller se tornassem baluartes de modernidade e eficácia.

\footnotetext{
${ }^{4}$ MARTINS, Romário. História do Paraná. Curitiba: Travessa dos Editores, 1995, p.114.

${ }^{5}$ Para maiores detalhes sobre as expedições dos Keller e suas relações com a Guerra do Paraguai, cf. KARPINSKI, op.cit., p.45-53.

${ }^{6}$ MELLO-LEITÃO, Cândido. História das expedições científicas no Brasil. São Paulo: Companhia Editora Nacional, 1941, p.153.

${ }^{7}$ NICOLAS, Maria. Sertanistas do Paraná: os esquecidos. [Curitiba]: Assembléia Legislativa, 1981, p.115.
} 
Em 1865, os Keller chegaram à Província do Paraná a fim de promover a exploração dos rios paranaenses que pudessem servir de comunicação com a Província do Mato Grosso. ${ }^{8}$ Além disso, conforme nos indica o relatório do vice-presidente Ermelino de Leão, esses engenheiros iniciaram a maior expedição realizada no rio Iguaçu até então, com a presença de agrimensores, tradutores e remadores que levariam oito canoas rio abaixo, partindo de São José dos Pinhais até onde as águas permitissem.

Nesse sentido, Leão documenta a notícia da exploração e detalha todas as providências que tomou para que esse trabalho fosse facilitado.Segundo ele, o governo da Província foi avisado da exploração no dia 13 de dezembro de 1865 e de que os engenheiros José e Francisco Keller deveriam receber o suporte necessário para que essa empresa tivesse êxito. Sendo assim, a Província se responsabilizou pela contratação do pessoal que auxiliaria os engenheiros que estavam sob as ordens do governo imperial. Nomeou-se um agrimensor, JulioKalkmann, pelo salário mensal de 80 mil réis, um intérprete, Antonio de Moraes Dutra, para colaborar num eventual encontro com os indigenas que habitavam aqueles territórios, e vários remadores, fechando a expedição com 24 homens.

Essa tripulação iniciou o trajeto "junto á ponte do rio Iguassú, na estrada que da capital se dirige a S. José dos Pinhaes, e d'ali partiram no dia 24 de junho [1866], data em que teve começo a exploração". ${ }^{9}$ Sendo que até 05 de novembro de 1866, data em que Leão apresentou o relatório ao Presidente Burlamaque, não havia notícia sobre o estágio da expedição.

Contudo, a expedição não logrou o êxito almejado, pois no dia 20 de novembro do mesmo ano foi cancelada pelo Presidente da Província Polidoro Cesar Burlamaque, devido, segundo o presidente, à constatação dos engenheiros de que o rio Iguaçu não se prestava à navegação à jusante de Porto da União. Segundo Burlamaque, os engenheiros José e Francisco Keller,

\footnotetext{
${ }^{8}$ MARTINS, op. cit., p.114.

${ }^{9}$ PARANÁ. Relatório do estado da Província do Paraná apresentado ao presidente, o illustrissimo e excellentissimo senhor doutor Polidoro Cesar Burlamaque pelo vice-presidente Dr. Agostinho Ermelino de Leão em 5 de novembro de 1866. Curityba: Typographia de Candido Lopes, 1867, p.11.
} 
mandaram oficios datados de 30 de Agosto e 2 de Novembro de 1866 onde relatavam dificuldades e embaraços insuperáveis à navegação do rio Iguaçu. ${ }^{10}$

A exploração estendeu-se até a localidade de Passo da Reserva, cerca de 30 léguas abaixo do porto da União. Provavelmente na confluência entre os rios Reserva e Iguaçu, região hoje pertencente ao município de "Reserva do Iguaçu" que, antes de sua emancipação, se chamava Rondinha e pertencia ao município de Pinhão. ${ }^{11}$ Segundo Burlamaque, os Keller oficiaram à presidência da província relatórios que afirmavam a existência de mais ou menos 90 saltos e corredeiras, além de enormes pedras que bloqueavam o leito do rio e que só com muito custo e despesas poderiam ser removidos. Para legitimar a ordem governamental da desistência da exploração, Burlamaqueafirmou em seu relatório que os engenheiros encontraram, além dos entraves gerados pelas pedras e corredeiras, muitas curvas e baixios que impediriam a navegação de navios com mais de dez toneladas de lotação. No entanto, essa opinião não é defendida pelos engenheiros Keller, o que, de certa forma, relativiza as afirmações tão específicas de Burlamaque e do governo provincial sobre o fracasso da expedição em questão.

No diário da viagem de José e Francisco Keller, emergem outros fatores que contribuíram para interrupção da viagem, não apenas as dificuldades impostas pelo rio Iguaçu. É certo que este rio, na opinião dos engenheiros, era de dificil aproveitamento para fins de navegação, mas disso não poderia ser auferido o insucesso da expedição. Não houve, por parte dos engenheiros, afirmações categóricas de que a viagem devesse ser interrompida. Muito menos que demonstrassem o desejo de desistir da expedição. Os motivos que nos detalham os engenheiros Keller em seu diário de viagem são preciosos para entendermos o contexto político e social de tal excursão e o

\footnotetext{
${ }^{10}$ PARANÁ. Relatório apresentado à Assembléa Legislativa do Paraná no dia 15 de março de 1867 pelo presidente da província o illustríssimo e excellentíssimo senhor doutor Polidoro Cezar Burlamaque. Curityba: Typographia de Candido Lopes, 1867, p.59.

${ }^{11}$ Para maiores detalhes cf. CLETO, José. No vale do Iguaçu. União da Vitória: Editora Livraria Cleto, 1953; TEIXEIRA, Murilo Walter. Marco Régio: municípios de Pinhão e Reserva do Iguaçu: retrospectiva histórica. [S.1.] : [S.n], 2006; e ZARDO, Eduardo Flávio. Inventário turístico de Reserva do Iguaçu. Curitiba: SEBRAE/DF, 2001. (Relatório final de Pesquisa).
} 
Gentes e paisagens do Rio Iguaçu na viagem expedicionária dos engenheiros Keller ...

conjunto de interesses imperial e provincial que se intercruzavam neste tipo de atividade "exploratória".

\section{O rio Iguaçu em diário: os Keller e a documentação da viagem}

Iniciaram os trabalhos expedicionários no dia 24 de junho de 1866 saindo de Curitiba com destino à ponte que havia sobre o rio Iguaçu nas proximidades de São José dos Pinhais. Devido às intensas chuvas e ao nível do rio estar 2,5 metros acima do que se considerava normal, ali ficaram até o dia 27 fazendo medições altimétricas e observações sobre o perfil transversal do vale do rio. Além disso, dividiram a tripulação e as cargas para cada uma das sete canoas que compunham a expedição, ${ }^{12}$ embora Ermelino de Leão tenha afirmado a saída de oito. Os relatórios das expedições dos engenheiros Keller obedeciam a uma estrutura capitular que, quase sempre, contava com um capítulo inicial onde eram transcritas as anotações do diário de viagem, seguidas de noções geológicas, climatológicas, medições hidrográficas, projetos para as vias de comunicação por terra e por água, cada uma dessas áreas estabelecidas em capitulo específico. Os relatórios contam também com mapas, desenhos, plantas dos sistemas hidrográficos percorridos e as conclusões pessoais dos autores. Especificamente sobre a exploração ao rio Iguaçu, o relatório subdividiu-se da seguinte forma:
A. Extracto do diário da expedição.
B. Noções geologicas e climatologicas sobre os terrenos percor- ridos.
C. Resultados da medição hydrographica.
D. Projectos para vias de communicação por terra e por água.
E. Conclusão. ${ }^{13}$

Neste artigoserá analisada somente a parte A, por ter sido publicada no Jornal Dezenove de Dezembro entre os meses de agosto e outubro de 1867. Nesta parte estão as análises gerais sobre o rio, as atividades e dificuldades da viagem e,

\footnotetext{
${ }^{12}$ KELLER, José; KELLER, Francisco. Relatório da exploração do rio Iguassú, feita em 1866 pelos engenheiros José e F. Keller. Jornal Dezenove de Dezembro, Curytiba, 31 de agosto de 1867 , n.817, p.3.

${ }^{13}$ Ibidem.
} 
principalmente, o despreparo da tripulação que, segundo os Keller, foi o principal motivo do término da viagem antes do previsto. Para os engenheiros, o êxito de suas expedições dependia, em grande parte, do empenho e trabalho dos tripulantes a quem chamavam de "camaradas". Pelo que se pode observar, este era um adjetivo comumente utilizado para designar uma condição de trabalho subalterna. Os Keller não designaram assim o agrimensor ou o intérprete, apenas os remeiros ou tripulantes incumbidos de levar as cargas ou de tarefas rotineiras como montar as barracas, fazer a comida, levar as correspondências. Pesou sobre estes trabalhadores a "culpa" da não conclusão da expedição.

Desde a apresentação do relatório, os Keller afirmam existir uma falta de engajamento e do que denominaram "qualidades physicas e moraes" ${ }^{14}$ da tripulação. De tal forma acreditavam nisso que afirmaram ser a escolha de tais homens o grande erro da exploração.

Reconheceu-se infelizmente, no decurso da viagem, que a escotha não tinha sido satisfactoria, resultando desse inconveniente, afinal dar-se por concluída a exploração, pelo Exmo. Sr. Presidente da província, antes de chegarmos ao Paraná. ${ }^{15}$

O desejo de José e Francisco Keller era o de engajar para a exploração do Iguaçu os mesmo "camaradas" que os acompanharam nas viagens ao Ivaí, Tibagi e Paranapanema. Faziam parte desta tripulação vinte moradores da Colônia Thereza ${ }^{16}$ contratados exclusivamente para a expedição como remeiros. $\mathrm{O}$ comportamento desses trabalhadores foi digno de nota no relatório sobre a respectiva viagem onde os engenheiros afirmaram se tratar de "boa gente" e "perfeitos canoeiros" que "em uma viagem longa, cheia de privações e de perigos, mostraram sempre o melhor ânimo e boa vontade, arrementendo aos trabalhos

\footnotetext{
${ }^{14}$ KELLER, José; KELLER, Francisco. Relatório da exploração do rio Iguassú, feita em 1866 pelos engenheiros José e F. Keller. Jornal Dezenove de Dezembro, Curytiba, 31 de agosto de 1867, n.817, p.3.

${ }^{15}$ Ibidem.

${ }^{16}$ Atual município de Ivaí, a Colônia Thereza foi fundada em 1847, às margens do Rio Ivaí, pelo médico francês João Mauricio Faivre. Segundo Romário Martins, em 1864, a população desta colônia era de 342 habitantes sendo elevada à categoria de Freguesia em 1871. Para mais informações, cf. MARTINS, op.cit., p.353.
} 
sem repugnância". ${ }^{17}$ No entanto, para a expedição ao Iguaçu, os Kellerafirmam que só puderam contar com a presença de três homens da Colônia Tereza, sendo necessário, então, engajar contra a sua vontade os outros membros "na ribeira de Iguape e em Morretes". ${ }^{18}$

A Ribeira do Iguape é um rico sistema pluvial existente nos limites entre os atuais estados do Paraná e São Paulo, cujas nascentes estão na Serra do Mar e correm em direção ao oceano Atlântico. No território paranaense, esse sistema recebe importantes afluentes como os rios Assungui, Pardo e Itapirapuã. Segundo Romário Martins, "o rio Ribeira do Iguape foi uma das mais frequentadas vias de penetração paulista no sertão do Guaíra, a partir do século XVII, quando os bandeirantes atingiram o Tibagi pelo sertão do Assungui". ${ }^{19}$ Sendo assim, há mais de dois séculos se fazia navegação com canoas sobre o rio Ribei$\mathrm{ra}$, de onde os engenheiros Keller engajaram os homens para a expedição ao Iguaçu.

Contudo, esta tradição secular de navegação em canoas não foi suficiente para capacitar tais canoeiros, conforme nos aponta o relatório da viagem dos Keller. Pelo que se percebe, a viagem foi marcada por uma série de conflitos entre a tripulação e os engenheiros a ponto de em vários momentos da narrativa estarem inscritos os relatos de baixas e queixas da falta de vontade dos camaradas em cumprir suas "obrigações". O fato é que, para os engenheiros, apenas o intérprete (Antonio Moraes Dutra), o agrimensor (Julio Kalkmann), os três camaradas advindos da "Colônia Thereza" e um pequeno número de canoeiros (os mais moços) contribuíram para a execução da exploração ao rio Iguaçu, "o resto, em parte não puderam no curso da viagem, em parte não quizeram cumprir com suas obrigações, dificultando elles, assim, a cada passo, o progresso da expedição". ${ }^{20}$

${ }^{17}$ KELLER, José; KELLER, Francisco. Exploração do Rio Ivahy. In: PARANÁ. Fala dirigida à Assembléia Legislativa Provincial do Parana à 15 de fevereiro de 1866 pelo presidente André Augusto de Pádua Fleury. Curityba: Typographia de Candido Lopes, 1866, annexo A, p.6. Arquivo Público do Paraná.

${ }^{18}$ Idem. Relatório da exploração do rio Iguassú, feita em 1866 pelos engenheiros José e F. Keller. Jornal Dezenove de Dezembro, Curytiba, 31 de agosto de 1867, n.817, p.3.

${ }^{19}$ MARTINS, op.cit., p.22.

${ }^{20}$ KELLER, José; KELLER, Francisco. Relatório da exploração do rio Iguassú, feita em 1866 pelos engenheiros José e F. Keller. Jornal Dezenove de Dezembro, Curytiba, 31 de agosto de 1867, n.817, p.3. 
Dentre os vários motivos que poderiam explicar a razão destes conflitos entre a tripulação e os engenheiros, acredita-se que um dos principais seja o modo distinto de compreender os rios e praticar a navegação com canoas. Os engenheiros não compreenderam estas especificidades dos habitantes das terras próximas ao litoral paranaense, principalmente dos locais onde os canoeiros foram selecionados. Certamente, estes povos não imaginavam como era o rio Iguaçu, pois suas experiências com navegação estavam pautadas nas características dos rios litorâneos. Por estarem quase ao nível do mar, estes rios possibilitavam uma navegação com menos entraves e, com isso, menos esforços aos canoeiros, bem diferente da realidade imposta por um rio que ultrapassa planaltos, como é o caso do Iguaçu. Desta forma, podemos inferir que os canoeiros contratados em Morretes e arredores não tinham a experiência necessária para os desafios impostos pelo rio Iguaçu e que, por isso, apresentaram um comportamento distinto, compreendido pelos engenheiros como fraqueza física e moral. Do relatório, extraímos a noção de fraqueza física como sendo aquela advinda de um corpo senil - já que os jovens foramapontados como exceção neste grupo - e que, no decurso da viagem, não puderam ou conseguiram cumprir com o contrato. Já a noção de fraqueza moral foi utilizada para desqualificar aqueles que, mesmo podendo continuar e contribuir com a jornada, não tiveram força suficiente para cumprir com a palavra empenhada no contrato de trabalho.

Por outro lado, os canoeiros que acompanharam os Keller nas expedições aos rios Ivaí, Tibagi e Paranapanema moravam às margens do rio Ivaí e, por isso, estavam acostumados com uma navegação dificil e que exigia muito dos remadores e canoeiros. Desta forma, ao navegar com os engenheiros, sua experiência foi interpretada como competência e força de vontade, resultando no sucesso das expedições em que trabalharam.

Toda essa discussão acerca das "qualidades" e "defeitos" da tripulação ajuda a compreender as diferentes relações sociais construídas nestas viagens e faz com que se relativize o papel do rio como o fator determinante para o sucesso ou insucesso da expedição. Para os Keller, o rio Iguaçu não era mais ou menos agressivo que os outros rios explorados, o que leva a 
deduzir que se não fossem os conflitos advindos das relações humanas, a viagem teria cumprido seu curso normal. Essas discussões possibilitam compreender também os diversos objetivos incrustados nestas viagens exploratórias. Diferentemente dos governantes, cujo objetivo era somente a verificação da possibilidade da navegação no rio Iguaçu, os engenheiros Keller demonstram que seus interesses estavam muito mais ligados à viagem em si do que às análises sobre a navegabilidade do rio. Muito mais do que caminhos navegáveis, os Keller procuravam explorar os territórios, conhecer a fauna, a flora, as populações e seus modos de vida e significação. Nesse processo, o rio deixa de ser o objeto principal da expedição e passa a agir como condição de possibilidade para aquilo que se constituiu como a principal busca dos engenheiros, a do conhecimento. Por isso, o ressentimento pela desistência da tripulação é a principal causa da culpabilidade imposta pelos engenheiros Keller aos membros escolhidos e contratados em Morretes.

Igualmente, por força do contrato com o governo, os engenheiros cumpriam também suas obrigações de formular mapas, plantas e projetos que viabilizassem a navegação nos rios explorados. Para isso, calculavam as despesas, indicavam o tipo de técnica a ser empregada e o tamanho dos navios que poderiam navegar nestes trajetos. Nesse sentido, seus relatórios são também importantes fontes para uma história das técnicas de navegação fluvial do Século XIX. Porém, no caso específico da viagem ao rio Iguaçu, entende-se que as relações com a tripulação e com a natureza são as principais contribuições destes engenheiros para a história das relações humanas com esse rio. O cotidiano da viagem fornece elementos imprescindiveis para interpretar o início de uma prática exploratória que, a partir de então, não mais cessou nas águas do rio Iguaçu, a do conhecimento. Conhecer no sentido de desnudar, de tornar visiveis suas características para, a partir daí, iniciar o processo de "humanização" do rio, entendida aqui como a ação de tornar o homem presente nestes espaços de água, florestas e solos férteis.

É importante lembrarmos que antes dessa viagem dos Keller, outras foram realizadas entre os anos de 1861 e 1862. Contudo, estas explorações retrataram apenas partes de possíveis trajetos.Por isso, embora a exploração dos Keller não tenha 
se concretizado até a confluência do Iguaçu com o Paraná, os relatórios sobre os trajetos percorridos por eles representam o todo das inúmeras partes visitadas e analisadas neste rio ao longo de vários anos no Século XIX. Além das medições hidrográficas, pluviométricas, altimétricas e de velocidade das águas, com vistas à descrição de possiveis espaços navegáveis, os Keller inserem um conteúdo inédito sobre o espaço natural (vegetação, minérios, fauna) e social (os povos que viviam às margens do rio e a aglomeração nos pequenos povoados, as relações de trabalho na viagem e, até mesmo, como os costumes alimentares determinaram rumos na expedição).

\section{Os Keller e a descrição dos recursos naturais do rio Iguaçu}

Sobre o espaço natural destacam-se as descrições e análises sobre a cobertura vegetal das margens, como elas influenciaram os rumos da expedição e como determinavam a paisagem ao longo do rio. No início da viagem, a paisagem marginal era composta por uma cerrada vegetação da qual se destacavam inúmeros cambuís (Myrciariatenella), "uma myrtacea de pouca elevação, cujos ramos não deixavam passagem alguma para as canoas". ${ }^{21}$ Por vezes, essa mirtácea, cuja família abrange espécies conhecidas como a jabuticabeira, pitangueira e guabirobeira, além de dificultar a passagem das canoas pelo rio, impedia também que os expedicionários encontrassem um lugar seco para o pouso. Conforme o rio ia se alongando e a vista dos engenheiros ganhava distância, outras espécies iam constituindo as florestas ao longo do Iguaçu dos anos 1860.

No dia 7 de Julho chegamos á pequena freguezia do Iguassú (Tindiquera), situada no alto, á margem direita do rio, com uma ponte sobre o mesmo. Continuavam as myrtaceas a formar quase que exclusivamente a vegetação das margens do rio, e só de vez em quando levantava um grupo de pinheiros nos lugares mais enxutos a sua coroa magestosa por cima dos outros arbustos. (grifo meu) ${ }^{22}$

\footnotetext{
${ }^{21}$ KELLER, José; KELLER, Francisco. Relatório da exploração do rio Iguassú, feita em 1866 pelos engenheiros José e F. Keller. Jornal Dezenove de Dezembro, Curytiba, 31 de agosto de 1867, n.817, p.3.

${ }^{22}$ Ibidem, p.4. 
Gentes e paisagens do Rio Iguaçu na viagem expedicionária dos engenheiros Keller ...

A presença da araucária (Araucariaangustifolia), que mais tarde se tornaria a árvore símbolo do Paraná, representa, na narrativa dos engenheiros, uma gradual mudança florestal de acordo com o avanço do rio no interior da provincia. Nas proximidades da capital, a paisagem era dominada por uma mirtácea que, embora formasse uma vegetação fechada e abundante, era, ainda assim, de pequeno porte e com baixo valor comercial. No entanto, à medida que o rio vai se alargando, possibilitando a visão de lugares mais distantes das margens e por isso enxutos, passam a se destacar outras espécies do que se convencionou chamar de floresta nativa. O pinheiro araucária, desde o século XIX, passa a ser descrito com adjetivos que o constitui como "o magestoso" ou "o rei" das matas paranaenses por seu imponente tamanho e valor comercial. É importante destacar que, mesmo aparecendo "de vez em quando", a araucária ganhou destaque na narrativa dos Keller e serviu de inspiração para a denominação do município que deu lugar à "Freguezia do Iguassú", o atual município de Araucária. ${ }^{23}$

Além das florestas nativas, pode-se perceber também que algumas ações de desmatamento já se mostravam em alguns pontos isolados e mais distantes das margens do Iguaçu. A presença de espécies cultivadas na descrição da paisagem demonstra a existência de ações exploratórias por entre as matas, sendo que a existência destas ações era intuída pela visão de espécies não nativas entre a vegetação. Sobre essas práticas, os engenheiros afirmam que "raras vezes se percebem, por entre uma vegetação cerrada, os morros dos campos mais distantes, com uma ou outra estância no meio dos pecegueiros plantados em roda". ${ }^{24}$ Pela visão de pequenas plantações de pessegueiros, José e Francisco Keller confirmam a prática estancieira nas proximidades da "Freguezia do Iguassú" que, desde a década de

${ }^{23}$ Por intermédio do Decreto $\mathrm{n}^{\circ} 40$ de 1890 , artigo $1^{\circ}$, o povoado da freguesia do Iguassú foi elevado à categoria de vila, com a denominação de "Araucária". Para mais informações sobre a história da "Freguezia do Iguassú", cf. ARAUCÁRIA: identidade, registro de sua história. Araucária: Prefeitura Municipal, 2003. (Cadernos Pedagógicos 1); e CARNEIRO JÚNIOR, Renato Augusto; BARCIK, Verginia. Da madeira ao aço: a industrialização de Araucária. Araucária: [s.d], 1999. (História de Araucária 4).

${ }^{24}$ KELLER, José; KELLER, Francisco. Relatório da exploração do rio Iguassú, feita em 1866 pelos engenheiros José e F. Keller. Jornal Dezenove de Dezembro, Curytiba, 31 de agosto de 1867, n.817, p.4. 
1860, representava a forma mais utilizada para sobrevivência dos habitantes daquela região.

Depois de terem passado o salto do Caiacanga, ${ }^{25}$ o que demorou cerca de dez dias, os Keller descrevem outro perfil tanto das águas do Iguaçu, quanto das formações rochosas e do solo o que, segundo eles, transformava consideravelmente a paisagem florestal. De seu relatório pode-se perceber que as transformações do rio operam as transformações da floresta que o margeia.

Desse ponto para baixo (quer dizer do fim do primeiro grupo de cachoeiras de 5 leguas de computo) [das quais o ponto culminante é o salto de Caiacanga] o caracter do rio e das margens muda inteiramente. [...] A vegetação também vai mudando consideravelmente quasidesapparecendo inteiramente as myrtaceas (cambuis), cujo logar tomam algumas bambonaceas (taquara, cresciuma, jetivoca, \&cc.), a palmeira jerivá e pinheiros, á sombra dos quaesapparece o ilex. ${ }^{26}$

Pela descrição dos engenheiros, constitui-se um quadro sinóptico da vegetação que acompanha o percurso do rio Iguaçu. No lugar dos cambuís que se emaranhavam por sobre a superficie e margens do rio, aparecem as taquaras, as palmeiras e os pinheiros que antes só apareciam nos lugares mais altos e enxutos. Outra planta muito importante para a economia paranaense também ganha destaque na descrição dos Keller, o ilex, a conhecida "erva-mate". Com este quadro de espécies, pode-se construir a paisagem vegetal das margens do rio Iguaçu ainda no Século XIX. Assim, percebermos que a atenção dos engenheiros não se fixou apenas nas mudanças de altitude, do tipo de solo e do clima por onde corre o rio. Entende-se que existe uma preocupação com o "conjunto", com o "todo" que forma a imbricada paisagem de rio e floresta e que adensa as noções dos recursos naturais pertencentes à Província do Paraná dos oitocentos.

\footnotetext{
${ }^{25}$ Segundo Maack, o "Caiacanga" é o primeiro dos inúmeros saltos do Iguaçu, com um desnível de nove metros e com volume médio de água de $54 \mathrm{~m}^{3} / \mathrm{seg}$. Está localizado nas proximidades de Porto Amazonas (cerca de $80 \mathrm{~km}$ de Curitiba) e sua formação é devida à passagem do primeiro para o segundo planalto paranaense. Mais detalhes cf. MAACK, Reinhard. Geografia física do Estado do Paraná. 2.ed. Rio de Janeiro: José Olympio; Curitiba: Secretaria da Cultura e do Esporte do Governo do Estado do Paraná, 1981, p.356.

${ }^{26}$ Idem. Relatório da exploração do rio Iguassú, feita em 1866 pelos engenheiros José e Francisco Keller. Jornal Dezenove de Dezembro, Curytiba, 14 de setembro de 1867, n.821, p.2.
} 
Além das florestas, a formação mineral dos territórios banhados pelo rio Iguaçu também foi discutida pelos engenheiros ao salientarem em seu relatório uma possível extração de "azougue" (Mercúrio-Hg) numa mina existente nos "campos do Castelhano", antiga estância do Portão, arredores do Salto Caiacanga (hoje município de Porto Amazonas). Ao relatar a existência desta mina, os engenheiros Keller possibilitam a afirmação de que entre junho de 1865 e junho de 1866 (período entre as expedições dos rios do norte da província e a expedição ao Iguaçu), eles permaneceram na Província do Paraná realizando pesquisas. Entre estas, eles relatam uma exploração à mina de Mercúrio citada no relatório da expedição ao Iguaçu:

Perto desse logar [Salto Caiacanga] se acha a barra do Ribeirão, em cujas cabeceiras nos campos chamados de Castelhano (antiga estância do Portão) se tem descoberto, ha annos, a mina de azougue, que em 1865 explorámos, indicando em nosso relatório o modo que se devia proceder para chegar ao conhecimento da riqueza e importanciadella. ${ }^{27}$

Novamente percebe-se o objetivo de agrupar o maior número possivel de informações sobre os recursos naturais nos territórios percorridos pelo Iguaçu. Além das descrições do rio e das florestas, as formações rochosas e o registro sobre a mina de Mercúrio enriquecem o relatório tornando-se um importante mapa de recursos naturais o que tende a legitimar a prática da exploração, já que, não se pode esquecer, os engenheiros eram pagos pela provincia para tal trabalho. Quanto mais riquezas apontassem em seus estudos, mais valiosas pareceriam suas expedições.

Por mais ricas que tenham sido as descrições sobre os espaços físicos e naturais do rio Iguaçu por onde passaram os Keller, as narrativas que mais contribuem para os objetivos deste artigo não são as que eles fizeram deliberadamente, mas sim as relações sociais inscritas nas entrelinhas do relatório. Os modos de vida, as relações de trabalho, a subsistência e os significados do rio para os povoados ribeirinhos, as formas de trabalho, os produtos de uma agricultura primária, os costumes alimentares e os sentimentos das populações ao perceberem

${ }^{27}$ KELLER, José; KELLER, Francisco. Relatório da exploração do rio Iguassú, feita em 1866 pelos engenheiros José e Francisco Keller. Jornal Dezenove de Dezembro, Curytiba, 14 de setembro de 1867, n.821, p.2. 
a presença dos "estrangeiros" no rio são fatores que emergem entre as descrições dos saltos e corredeiras, da vegetação, dos minérios e da fauna. Está nessas poucas linhas, que saltam da narrativa central, a principal contribuição dos Keller para estabelecermos um diálogo sobre as formas de sociabilidade regional que, de certo modo, foram possibilitadas pela presença do rio Iguaçu.

\section{Modos de vida e significados do rio Iguaçu aos ribeirinhos em 1866}

Durante a expedição, os Keller relatam a passagem por três povoados significativos: "freguezia do Iguassú" (Araucária-PR), "porto da União" (União da Vitória-PR) e "passo do Iguassú" (Passo da Reserva-PR). Pelo relatório, todas estas localidades nasceram e tiveram sua existência atrelada ao rio Iguaçu de onde chegavam as canoas que navegavam nesses trajetos ou por onde passavam as tropas de gado, cavalo ou mula nas picadas que interconectavam Curitiba, Palmeira, Ponta Grossa e Guarapuava aos Campos de Palmas. "Porto da União" era um espaço conhecido desde 1842 por estar nas proximidades do local por onde se podia fazer, com maior facilidade, a travessia do gado pelo rio Iguaçu. Este local, conhecido como "passo" ou "vau" do Iguaçu, foi "descoberto" pelo bandeirante paranaense Coronel Pedro de Siqueira Cortes. A partir de então, passou a ser entreposto na picada que ligava as localidades de Palmeiras a Palmas.

Segundo José Júlio Cleto da Silva ${ }^{28}$, é certo que "Porto da União" nasceu do encontro de comissões que exploravam a

\footnotetext{
${ }^{28}$ José Julio Cleto da Silva nasceu em 1888 e em 1894, chegou a Porto da União da Vitória quando seu pai, José Cleto da Silva (1843-1912) lá se instalou como educador e fundador de um colégio que funcionaria nos regimes de internato e de externato até 1899 . Entre 1910 e 1917, José Julio Cleto da Silva destacou-se na política do Paraná devido a sua luta para não entregar o território paranaense contestado por Santa Catarina, cuja linha divisória tomaria parte da cidade de União da Vitória (PR) formando a nova cidade de Porto União (SC). Morreu em 1953 deixando vários livros e textos sobre a região de União da Vitória (PR). Sobre alguns aspectos de sua vida e obras cf. THOMÉ, Nilson. A formação do homem do Contestado e a educação escolar - República Velha. 349 f. Tese (Doutorado em Educação). Faculdade de Educação. Universidade Estadual de Campinas, Campinas, 2006. Disponível em: $<$ http://libdigi.unicamp.br/document/?code=vtls000411820>. Acesso em: $17 \mathrm{abr}$. 2010; SILVA, Cleto da. Accordo Paraná Santa Catharina ou O Contestado diante das carabinas. Coritiba: Globo, 1920.
} 
região banhada pelo Iguaçu. Tal encontro poderia ser das comissões de Siqueira Cortes e José Pereira dos Santos, já que ambas saíram em abril e maiode 1839, respectivamente, com o intuito de encontrar e tomar posse dos campos de Palmas, ou ainda, de comissões militares que tivessem saído em expedição pelo rio Iguaçu, uma subindo e outra descendo o rio. Como essa região era conhecida também como "Entreposto de Nossa Senhora da Vitória", o encontro entre as comissões designaria o nome da localidade como Porto da União ou Porto da União da Vitória. ${ }^{29}$

Das três localidades visitadas pelos engenheiros Keller em 1866, sem dúvida "porto da União" foi a que mais se caracterizava como "povoado". Embora não houvesse mais do que trinta casas cobertas de palha, este local representava o maior centro populacional desde que os Keller deixaram Curitiba. Os modos de vida desses habitantes pouco são descritos no relatório, mesmo assim, percebe-se a extrema ligação com o rio, pois para os engenheiros, o que "dava certa importancia ao logar" era "a passagem das tropas e boiadas no rio", o que se fazia a nado por se tratar de um espaço de pouca profundidade. ${ }^{30}$

De forma memorialística, o autor Cleto da Silva procurou reconstruir, em 1933, o espaço social de Porto da União da Vitória entre os anos de 1860 e 1876. Seu trabalho ajuda a compreender alguns traços do cotidiano dos habitantes encontrados pelos Keller em 1866. Em seu livro "Antecedentes históricos de União da Vitória", Cleto da Silva procurou reproduzir, em texto e figuras, o pequeno povoado nascido às margens do rio Iguaçu e que dele quase dependia exclusivamente.

Através de um croqui feito em 1933, Cleto da Silva traçou o espaço ocupado pelo povoado de "porto da União" entre os anos de 1860 e 1876 . Para esse desenho, contou com a ajuda de antigas plantas da cidade de União da Vitória e, principalmente, com os depoimentos de antigos moradores e familiares, já que seu pai, José Cleto da Silva, vivia neste povoado desde 1894. Esta "imagem de memória" reconstruiu o lugarejo, apontando

${ }^{29}$ SILVA, Cleto da. Apontamentos históricos de União da Vitória (1768-1933). Boletim do Instituto Histórico, Geográfico e Etnográfico do Paraná, Curitba, vol. XXX, 1976, p.37-38.

${ }^{30}$ KELLER, José; KELLER, Francisco.Relatório da exploração do rio Iguassú, feita em 1866 pelos engenheiros José e Francisco Keller. Jornal Dezenove de Dezembro, Curytiba, 21 de setembro de 1867, n.823, p.1. 
as formas primárias de sociabilidade e, possivelmente, o povoado encontrado pelos Keller em 1866.

Pelo desenho da Figura 01, percebe-se o traçado da "picada" (estreito caminho) que cruzava o rio e o vilarejo, as 31 casas de moradia numeradas e com o nome dos moradores, as poucas ruas que sempre se encontravam com a estrada por onde passava a tropa, a existência de um pequeno monjolo (engenho acionado à água para pilar o milho) no centro do povoado, o rio Iguaçu, onde se destaca bem o local de passagem dos bois, e dois capões de mato.

Figura 1. Croqui de União da Vitória nos anos de 1860-1876

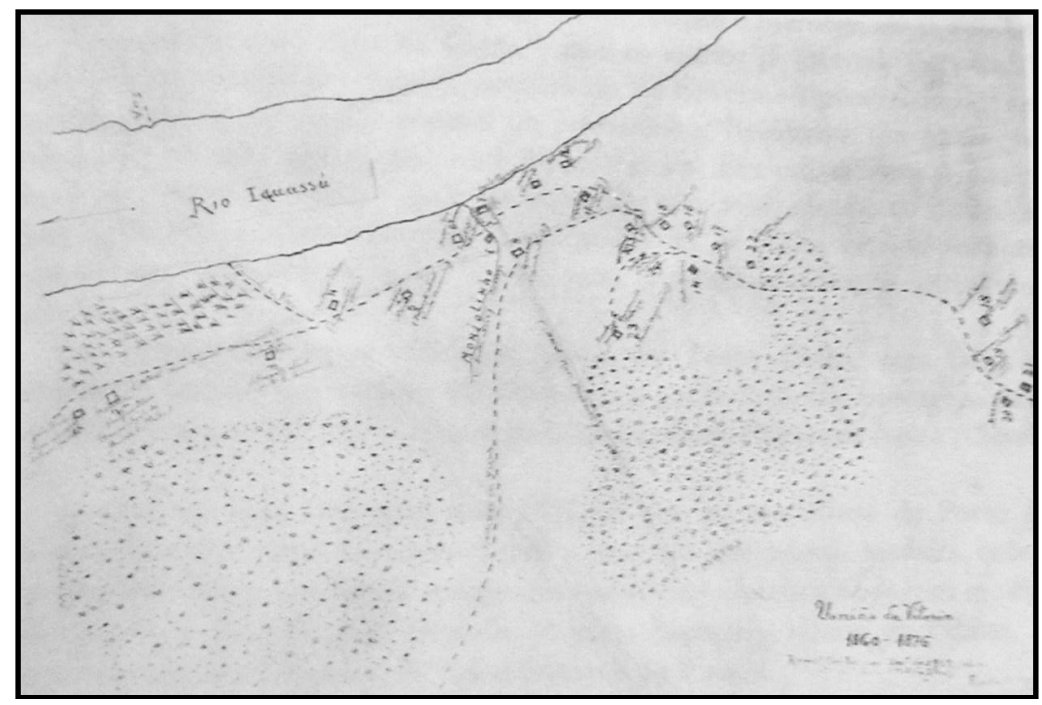

Fonte: Silva (1976) $)^{31}$

O desenho de Cleto da Silva destaca bem a curva e o local mais largo do rio Iguaçu por onde passavam as tropas que davam a "importância" ao lugar como destacaram os engenheiros Keller. Também coincide o número de casas, já que o croqui enumera 31 casas e o relatório dos Keller aponta a existência de

${ }^{31}$ SILVA, Cleto da., op.cit., entre p.40 e 41. 
"20 a 30 casinhas cobertas de palha", 32 o que também demonstra que entre 1866 e 1876, ano da visita dos Keller e data limite do croqui, pouca coisa mudou na localidade.

O caminho que ligava Palmeiras a Palmas cruzava o povoado que convivia constantemente com a presença de tropas e tropeiros, bem como com todos os efeitos que esta espécie de "nomadismo" impunha em seu cotidiano. No entanto, as pessoas que ali fixaram moradia procuravam, segundo Cleto da Silva, construir um espaço também de permanência com certa vida social e cultural que fosse capaz de subsistir às constantes influências do estilo de vida tropeiro. Na década de 1860, já moravam no povoado o sapateiro Antonio Joaquim de Castilho e o manobrista de canoas João Antonio do Espírito Santo, responsável pela travessia de inúmeras canoas que ali aportavam. O sapateiro era também um eximio tocador de viola que sabia fazer "porfia" em regra, isto é, disputas poéticas em forma de diálogo cantado e improvisado mostrando, assim, possiveis modos de convivência em torno dos desafios cantados e acompanhados pela viola. Em 1863, existiam 18 casas de madeira, a maioria coberta de tábuas e palha, mas uma, a do músico, era já coberta de telhas de barro fabricadas por ele e sua família. ${ }^{33}$

Com esse traçado de "Porto da União", percebe-se como este ambiente ribeirinho influenciou a constituição e o cotidiano do povoado que, além de ter se formado por estar num local específico do rio Iguaçu, sofria as constantes transformações sociais, culturais e ambientais proporcionadas pelos eventos que emanavam do rio. Dele é que vinham as tropas que traziam novos ou velhos viajantes, por ali chegavam mercadorias e advinham mudanças ou permanências sociais e culturais do lugarejo. No aspecto ambiental, é preciso levar em conta as transformações ocorridas nas margens pelos eventos naturais da estiagem e da chuva. Com tempo seco e águas baixas, aumentava-se o número de tropas, pois o rio favorecia uma passagem rápida e livre de empecilhos à boiada. Porém, quando principiavam as chuvas que desencadeavam as enchentes, as tropas sumiam e a vila

${ }^{32}$ KELLER, José; KELLER, Francisco. Relatório da exploração do rio Iguassú, feita em 1866 pelos engenheiros José e Francisco Keller. Jornal Dezenove de Dezembro, Curytiba, 21 de setembro de 1867, n.823, p.1.

${ }^{33}$ SILVA, Cleto, op.cit. p.40-42. 
sofria com o avanço das águas sobre as casas e construções existentes ao redor do rio. Sendo assim, o rio era a condição de possibilidade de sobrevivência dos habitantes ribeirinhos, tanto dos trabalhos que envolviam a passagem de gado pelo "passo" quanto dos que resultavam da pequena navegação que se fazia em canoas desde meados do Século XIX, como veremos no próximo item.

\section{Hábitos e subsistência econômica dos ribeirinhos na década} de 1860

Boa parte da renda dos habitantes de "porto da União", na segunda metade do Século XIX, advinha das atividades de passagem das tropas de gado. Da mesma forma, a localidade de "Passo do Iguassú" também sobrevivia dos serviços que prestavam aos que realizavam tal travessia em outro espaço favorável a este tipo de atividade. Segundo os Keller, 30 léguas (180 $\mathrm{km}$ ) à jusante de "porto da União" também existia um "vau" no rio Iguaçu por onde passavam, anualmente, aproximadamente dois mil bois, quatro mil mulas e cinco mil cavalos vindos do Sul do Império com destino a Sorocaba, Província de São Paulo. ${ }^{34}$ Ao chegar a Passo do Iguaçu, atual município paranaense de Passo da Reserva, no dia 30 de outubro de 1866, os Keller encontraram algumas "casinhas". Sobre os habitantes do local, citaram o nome do morador que os acomodou, Serafim Baptista Carvalho, e reafirmaram a dependência econômica do lugarejo aos poucos réis que ganhavam ajudando a travessia das tropas: "A população do logar que mora em quatro ou cinco casas na margem esquerda, vive em grande parte do que elles ganham quando ajudam a tocar e passar as tropas e boiadas". ${ }^{35}$

Entretanto, outras formas de sobrevivência também foram apontadas pelos Keller entre os moradores dos povoados visitados. Em "freguezia do Iguassú", já havia estâncias ou fazendas de gado, cujas sedes foram avistadas pelos Keller quando navegavam o Iguaçu e descreviam as plantações de pesseguei-

${ }^{34}$ KELLER, José; KELLER, Francisco.Relatório da exploração do rio Iguassú, feita em 1866 pelos engenheiros José e Francisco Keller. Jornal Dezenove de Dezembro, Curytiba, 5 de outubro de 1867 , n.827, p.2.

${ }^{35}$ Ibidem. 
Gentes e paisagens do Rio Iguaçu na viagem expedicionária dos engenheiros Keller ...

ros que as rodeavam. ${ }^{36}$ Já em "porto da União", os Keller relatam o cultivo de feijão, milho e mandioca nas áreas mais à Oeste da povoação, onde se tiravam boas colheitas que auxiliavam na subsistência da localidade. ${ }^{37} \mathrm{O}$ cultivo destes gêneros possibilita traçar um costume alimentar dos habitantes de "porto da União" que acabou por desencadear uma série de contratempos durante a expedição dos Keller. Durante a viagem, a falta da farinha de milho fez com que a expedição parasse até que alguém conseguisse trazer uma quantidade suficiente deste produto alimentício para os "camaradas" que faziam parte da exploração.

Quando saíram de "porto da União", no dia 3 de setembro de 1866, os engenheiros calcularam as medidas diárias de comida até a data da provável chegada à próxima localidade que seria Passo do Iguassú. Essa medida era chamada de "ração diária" que não poderia deixar de contar com a farinha de milho, por se tratar de um alimento apreciado pelos camaradas. No entanto, entre os dias 13 e 21 de setembro, quando já estavam a mais de dez dias de viagem de "porto da União", choveu sem parar, fazendo com que o rio subisse mais de 3 metros, molhando todos os livros, instrumentos e mantimentos da expedição. No entanto, o maior problema que essa chuva causou foi que a farinha de milho estava acabando e, sem ela, os camaradas não trabalhavam.

Os mantimentos, e especialmente a farinha de milho, á qual os camaradas são de tal modo acostumados que não querem trabalhar sem ella, ainda mesmo que, afora isso, tivessem tudo - mais, estava-se acabando em consequencia da demora pelo estado pessimo do tempo. Julgámos portanto prudente mandar buscar uma certa quantidade no porto da União, emquanto a distancia, que em linha recta não era grande, ainda o permittia. ${ }^{38}$

Pelo que se percebe, a farinha não era o alimento indispensável para os Keller que provavelmente se alimentavam do "tudo o mais" tipos de alimentos. Contudo, por conta do hábito

\footnotetext{
${ }^{36}$ Idem. Relatório da exploração do rio Iguassú, feita em 1866 pelos engenheiros José e Francisco Keller. Jornal Dezenove de Dezembro, Curytiba, 31 de agosto de 1867, n.817, p.4.

${ }^{37}$ Idem. Relatório da exploração do rio Iguassú, feita em 1866 pelos engenheiros José e Francisco Keller. Jornal Dezenove de Dezembro, Curytiba, 21 de setembro de 1867, n.823, p.1.

${ }^{38}$ KELLER, José; KELLER, Francisco. Relatório da exploração do rio Iguassú, feita em 1866 pelos engenheiros José e Francisco Keller. Jornal Dezenove de Dezembro, Curytiba, 21 de setembro de 1867, n.823, p.2.
} 
dos camaradas só trabalharem se comessem a farinha de milho, a expedição sofreu ainda maior atraso, pois mesmo depois de parar a chuva, a comitiva teve que esperar a volta daqueles que buscavam a farinha de milho moída, provavelmente no monjolinho que existia no centro do povoado. Desta forma, percebe-se que o cultivo do milho era de suma importância para a localidade, pois o consumo da farinha desse grão era um hábito tanto dos moradores do povoado quanto dos viajantes, principalmente os trabalhadores, fossem eles tropeiros ou canoeiros.

\section{Formas, relações e cultura de trabalho entre ribeirinhos, tropas e navegadores}

Por intermédio do diário de viagem dos engenheiros Keller, é possivel reconstituir, até certo ponto, algumas formas e relações de trabalho tanto entre os ribeirinhos que auxiliavam a navegação em canoas, quanto as nutridas na própria viagem dos Keller. Em seus relatos, emerge uma série de relações travadas entre eles e os camaradas, entre aqueles que eles consideravam aptos moral e fisicamente para o trabalho e os que não se adequaram às suas normas de trabalho. As ações de dispensa e contratação, bem como alguns conflitos e dificuldades para encontrar pessoas para esse tipo de trabalho, permeiam o discurso dos Keller sobre formas, relações e cultura de trabalho.

Desde o início de seu relatório, os Keller deixaram claro seu descontentamento com a tripulação, a ponto de culpá-la pelo término prematuro da viagem. Assim que chegaram a "freguezia do Iguassú" (primeira localidade após Curitiba), no dia 07 de julho de 1866, despediram dois tripulantes, "um por falta de forças sufficientes e o outro por ter falta de pratica de semelhante serviço" ${ }^{39}$ Com essa dispensa, a tripulação ficou incompleta e a ausência desses dois homens foi sentida durante toda a viagem, como relataram os Keller ao chegar em "porto da União", no dia 29 de agosto de 1866, onde tentaram "completar o numero da tripolação das canôas, que pela sahida dos dous camaradas na freguezia do Iguassú era insufficiente, falta esta tanto mais sensivel quanto sempre acontecia estarem um ou

\footnotetext{
${ }^{39}$ Idem. Relatório da exploração do rio Iguassú, feita em 1866 pelos engenheiros José e Francisco Keller. Jornal Dezenove de Dezembro, Curytiba, 31 de agosto de 1867, n.817, p.4.
} 
dous doentes". ${ }^{40}$ As doenças que impediam o trabalho de alguns homens durante a expedição estavam ligadas às condições do próprio trabalho. O "reumathismo" 41 foi a enfermidade citada pelos Keller, doença associada ao fato de que, durante todos os dias da viagem - que se deu no inverno - os camaradas permaneciam molhados. O frio e a umidade faziam com que se agravasse o estado de saúde dos camaradas, principalmente nos períodos de chuva quandonão podiam gozar de roupas e leitos secos, nem mesmo no período da noite.

Sendo assim, todas as medidas, ordens e atitudes impostas à tripulação pelos Keller interferiam drasticamente no andamento da viagem que dependia, exclusivamente, das formas de trabalho impostas aos camaradas. Entre "freguezia do Iguassú" e "porto da União", não havia um número necessário de pessoas disponíveis para os trabalhos da expedição que teve que continuar com a ausência de dois tripulantes durante 53 dias. Essa falta de pessoal também agravava a situação nos locais onde não era possivel a passagem das canoas pelo leito do rio, como foi o caso na passagem pelas corredeiras que antecederam o Salto Caiacanga. Os engenheiros relatam a existência de uma série de cachoeiras e correntezas antes do referido salto que, juntas, somavam mais de 5 léguas $(30 \mathrm{~km})$. Segundo os Keller, com muito custo, apenas as canoas conseguiriam passar desde que retiradas do rio e carregadas por terra nos saltos maiores. Com isso, a carga deveria ser transportada por terra durante todo o trajeto, o que necessitaria de uma tropa específica para tal trabalho. Como a expedição só contava com canoas e remadores, tiveram que procurar alguém para realizar este serviço.

Tratamos de alugar uma tropa para o transporte, mas só n'uma estancia mais distante foi-nos possivel chegar a um accordo, por se nos ter exigido na proximidade quantias tão avultadas que importavam em mais do que o valor da carga, a qual, na mór parte, consistia em mantimentos e ferramenta. ${ }^{42}$

\footnotetext{
${ }^{40}$ KELLER, José; KELLER, Francisco. Relatório da exploração do rio Iguassú, feita em 1866 pelos engenheiros José e Francisco Keller. Jornal Dezenove de Dezembro, Curytiba, 21 de setembro de 1867, n.823, p.1.

${ }^{41}$ Ibidem.

${ }^{42}$ Idem. Relatório da exploração do rio Iguassú, feita em 1866 pelos engenheiros José e Francisco Keller. Jornal Dezenove de Dezembro, Curytiba, 14 de setembro de 1867, n.821, p.2.
} 
Esse trecho do relatório é significativo, pois insere no contexto da viagem uma série de relações travadas entre os engenheiros e os moradores da região explorada. O fato de ser maior o valor cobrado pelos moradores que viviam nas proximidades das cachoeiras denota que estes habitantes eram conscientes das dificuldades de encontrar pessoal disponivel para tais serviços. Por isso, agregavam ao preço a vantagem de estarem nas proximidades do rio que, na época da viagem dos Keller, era relativamente trafegado por canoas. Por outro lado, a negativa dos Keller em utilizar o serviço desses moradores ribeirinhos indica também as estratégias dos engenheiros para contratar os trabalhos que serviriam à expedição. Isso fez com que extrapolassem os limites do rio na busca por melhores preços e levou-os a travarem relações de trabalho com vários habitantes, como aqueles da fazenda mais distante com quem acabaram fechando o negócio.

Nos relatos sobre "porto da União", é possivel perceber algumas singularidades nas relações de trabalho, pois nessa localidade se entrecruzavam a agricultura, os serviços prestados às tropas e os empregos na navegação das canoas. Os Keller não relataram as características dos trabalhos ligados ao tropeirismo, contudo, eles insistiram na importância da navegação para a subsistência dos habitantes de "porto União".

Um pequeno numero dos habitantes se emprega na navegação fluvial, trazendo sal em grandes canôas do rio das Arêas, pequeno afluente do Iguassú, cuja barra fica na altura das Palmeiras, distante sete léguas, até porto da União, sendo daqui o transporte no ponto do destino effectuado por terra em cargueiros. ${ }^{43}$

Não há como especificar o trajeto de tal navegação e nem é o intuito deste trabalho delimitá-la, porém, essa afirmação dos Keller contribui para que se perceba como era importante e cotidiana a navegação por canoas no rio Iguaçu e seus afluentes no início da instalação da Província do Paraná. Além de ser uma atividade que beneficiava a criação de gado, pois era o sal o principal produto transportado nas canoas, nela se empregavam alguns ribeirinhos. No entanto, para os Keller, esses

\footnotetext{
${ }^{43}$ KELLER, José; KELLER, Francisco. Relatório da exploração do rio Iguassú, feita em 1866 pelos engenheiros José e Francisco Keller. Jornal Dezenove de Dezembro, Curytiba, 21 de setembro de 1867 , n.823, p.1.
} 
Gentes e paisagens do Rio Iguaçu na viagem expedicionária dos engenheiros Keller ...

habitantes que trabalhavam na navegação cobravam muito pelos fretes e eram descuidados com as mercadorias, fazendo com que o "próspero" negócio da navegação declinasse por culpa dos próprios canoeiros.

Esta pequena navegação, que merecia melhor sorte, está actualmente declinando em grande parte por culpa dos proprios canoeiros, que pedindo fretes exorbitantes não tomam a cautela necessaria no transporte, e trazem muitas vezes as cargas avariadas ao porto do desembarque. ${ }^{44}$

Além dos altos preços cobrados pelo frete, os Keller indicam problemas de ordem estrutural como o tipo de canoa e a falta de uma política que visasse melhorias na navegação na parte navegável do rio Iguaçu.

Seria fácil remediar esses inconvenientes com a construção de barcos maiores de fundo chato (que carregam mais e demandam de menos agua que canoas estreitas), guarnecidos com toldas, dando desse modo um novo impulso a essa parte do valle do rio Iguassú, o qual, gozando de uma communicação fluvial de 50 léguas de comprimento, até agora é quasi um deserto. ${ }^{45}$

Canoas estreitas e sem toldas eram os instrumentos de trabalho de alguns habitantes que teimavam em levar adiante uma navegação precária e cara, na opinião dos Keller. Também segundo os engenheiros, desde que resolvidos os problemas estruturais, a navegação era a atividade que poderia tirar a região do atraso e povoá-la. Entretanto, conforme apontou AlvirRiesemberg, ${ }^{46}$ a principal causa da precariedade desta navegação por canoas no vale do Iguaçu era de ordem cultural e não estrutural como apontaram os Keller. Segundo Riesemberg, os primeiros povoadores do vale do Iguaçu como um todo e, especificamente, "porto da União" (União da Vitória-PR) "levaram para ali a cultura curitibana, cujos elementos essenciais foram elaborados nas lides das fazendas de criação e das lavouras. Eram as tropas, a cultura do milho e do feijão, a indústria da erva-mate e das farinhas." ${ }^{47}$ Nesse sentido, estes primeiros

\footnotetext{
${ }^{44}$ Ibidem.

${ }^{45}$ Ibidem.

${ }^{46}$ RIESEMBERG, Alvir. A instalação humana no vale do Iguaçu. [S.1. s.n.], 1973, p.54.

${ }^{47}$ Ibidem, p.53.
} 
moradores tiveram que se adaptar ao trabalho no rio, um ambiente que possibilitava formas distintas de sua cultura de trabalho.

Riesemberg critica a forma pejorativa com a qual os engenheiros Keller trataram os primeiros navegadores do Iguaçu em 1866. Para ele, os engenheiros se equivocaram ao atribuir ao desleixo e à ganância dos canoeiros do Iguaçu o pequeno desenvolvimento que tivera até então o transporte fluvial. "Para aquela gente dos campos gerais, criada a tanger tropas, a canoa, como meio de transporte, era elemento cultural novo, ao qual ainda era mister adaptar-se". ${ }^{48}$ Sendo assim, pode-se afirmar que a navegação no rio Iguaçu é um fato estabelecido num longo processo de adaptação cultural com o meio hídrico. As mudanças culturais relacionadas ao meio ambiente e aos novos oficios que o rio Iguaçu possibilitava foram tão decisivas quanto as mudanças estruturais e politicas que visavam impulsionar a navegação no trecho propício para essa atividade.

Da mesma forma que os Keller deixaram transparecer pouca simpatia pelos habitantes de "porto da União", estes também mostraram desconfiança e desinteresse pela expedição. Por parte dos engenheiros, o principal motivo dessa antipatia era a forma como os habitantes daquele povoado encaravam o trabalho. Nos relatos dos Keller, fica subentendido que o atraso da localidade era culpa dos seus moradores que não sabiam aproveitar as possibilidades que ali existiam, tanto a fertilidade do solo para incrementar o cultivo de outros produtos agrícolas, como o arroz e a cana-de-açúcar, quanto os recursos de navegação no rio Iguaçu. Além disso, houve ainda conflitos de ordem pessoal, pois segundo os Keller, os habitantes do lugarejo não aceitavam a presença de outras pessoas explorando o rio, uma tarefa que eles tentavam há anos fazer e não conseguiam. A presença dos Keller representava uma ofensa aos moradores do povoado, por isso, além de não aceitarem trabalhar como canoeiros para a expedição, eles passaram a espalhar entre a tripulação rumores de perigos e muito trabalho na parte que percorreriam a jusante do porto.

${ }^{48}$ Ibidem, p.54. 
Gentes e paisagens do Rio Iguaçu na viagem expedicionária dos engenheiros Keller ...

Infelizmente aos rumores de novos e grandes perigos e trabalhos, pelos quaeshaviamos de passar, espalhados entre nossa gente, pelos habitantes do porto da União, cujo brio se achava naturalmente offendido pela razão de que outros haviam de levar a effeito o que elles por diferentes vezes projectaram e tentaram debalde, isto é, varar até o - Passo -, esses rumores, digo, faziam sobre o espirito de nossa gente, um tanto alquebrada pelos passados trabalhos na Caiacanga, a mais funesta impressão e pouco faltou que elles nos tivessem abandonado neste logar. ${ }^{49}$

Dessa narrativa, pode-se perceber como o conhecimento dos ribeirinhos acerca do rio Iguaçu no trecho posterior ao povoado não fora levado em conta pelos engenheiros. De certa forma, havia já a consciência da formação de grandes saltos e corredeiras intransponiveis por qualquer embarcação que formava um saber popular sobre as características e os perigos do rio Iguaçu. Pelo que aponta AlvirRiesemberg, ao falar especificamente sobre os canoeiros de Porto da União, essa recusa da população local não fora motivada apenas por amor próprio ofendido. "Na verdade, aquele trecho de rio do vau até o Passo já seria conhecido dos fazendeiros de Palmas que, desde o início do povoamento dos campos, procuraram um porto favorável à passagem das boiadas e navegação fluvial". ${ }^{50} \mathrm{O}$ contato entre habitantes e canoeiros residentes em "porto da União" e a tripulação da expedição dos Keller fez com que se propagassem esses juízos sobre o rio, aumentando, assim, o medo de seguir adiante.

A divulgação destes "rumores" populares foi apontada pelos Keller como tática de uma população descontente com a presença de "outros" fazendo o que eles deveriam ter feito. No entanto, no decorrer da expedição, percebe-se que não eram apenas "rumores", pois o perigo era real e muitas perdas ocorreram durante o trajeto. Pode-se afirmar também que a não conclusão da expedição, cuja culpa os Keller incutiram à tripulação despreparada e inábil, mexeu também com o "brio" dos engenheiros. Afinal, como antecederam os canoeiros de "porto

\footnotetext{
${ }^{49}$ KELLER, José; KELLER, Francisco. Relatório da exploração do rio Iguassú, feita em 1866 pelos engenheiros José e Francisco Keller. Jornal Dezenove de Dezembro, Curytiba, 21 de setembro de 1867, n.823, p.1.

${ }^{50}$ RIESEMBERG, Alvir. A Nau de São Sebastião. Curitiba: Instituto Histórico, Geográfico e Etnográfico do Paraná, 1978, p.62.
} 
da União", em muitos momentos, a expedição teve que abrir mão da navegação e transportar as canoas e a carga por terra. Além disso, em alguns locais em que os estudos dos engenheiros davam por certa a passagem por água, as embarcações encalhavam ou eram lançadas ao fundo do rio, onde perderam mantimentos, roupas, barracas, instrumentos e, por pouco, não perderam a vida.

\section{Considerações finais: os Keller e suas contribuições para a história regional do "Médio Vale do Iguaçu"}

Pelo que foi discutido aqui, pode-se concluir que o relatório elaborado pelos engenheiros Keller a partir do diário da viagem ao rio Iguassú, feita entre junho e novembro de 1866, apresenta bem mais do que as descrições naturais. O relatório em questão é um documento que possibilitou o registro de uma série de relações e situações vividas não apenas pelos responsáveis pela exploração. Juntam-se às descrições geológicas, geográficas e hidrográficas do rio Iguaçu, as formas de vida dos habitantes ribeirinhos e sua rica história de dependência, adaptação e utilização dos recursos advindos do rio ou por ele possibilitados.

Além disso, é importante perceber que a expedição dos engenheiros Keller foi a primeira a documentar mais de quatro meses de descrições, análises, críticas e estudos sobre o rio Iguaçu e sua influência na economia e na cultura de uma sociedade regional. Uma exploração desse porte sobre as águas do Iguaçu em 1866 representou também a expectativa da Província e do Império de tornar este rio navegável, de encontrar outras vias de acesso ao interior da provincia e às fronteiras internacionais em época de tantos conflitos, pois não se pode esquecer de que nesta mesma época travava-se a Guerra do Paraguai.

Com a entrega dos relatórios feitos pelos engenheiros Keller, os governantes desistiram de constituir a navegação no rio Iguaçu à jusante do porto da União e procuraram intensificar e incrementar a navegação no único trecho possivel de percorrer a barco que já se fazia desde o início da instalação da Província: entre o Salto Caiacanga e o Porto da União. Sendo assim, a releitura desses documentos possibilita compreender as relações históricas entre o rio Iguaçu e a região percorrida 
por ele. O relato da expedição dos Keller, especificamente, faz com que se encerrem nos relatórios de Presidente da Província as especulações em torno de uma possível ligação territorial de leste a oeste do Paraná através do rio Iguaçu.

Resumo: Este artigo analisa o relatório da expedição ao rio Iguaçu feita em 1866 pelos engenheiros Keller e a relação histórica entre a construção da paisagem e a do espaço que se convencionou chamar de "Região do Médio Vale do Iguaçu". Um dos objetivos é o de perceber como as descrições sobre o rio Iguaçu e suas características contribuem para as discussões historiográficas sobre a região. No caso específico do documento produzido pelos Keller, é possível perceber uma ligação discursiva entre rio, interesses governamentais e a rede de sociabilidades que se constituiu em torno de suas margens. Das descrições sobre os espaços físicos e naturais do rio Iguaçu por onde passaram os Keller, escapam narrativas instigantes sobre os ribeirinhos e seus modos de vida.

Palavras-chave: Rio Iguaçu. Paisagem. Meioambiente. História regional.

Abstract: This article analyses the report of the expedition along the Iguaçu River made in 1866 by the Keller engineers and the historical relations between the landscape and the development of the area commonly known as "Região do Médio Vale do Iguaçu". The main purpose of this discussion is to understand how the descriptions of the Iguaçu River and its characteristics contribute to the historiographical debates about the region. In the specific case of the document produced by the Kellers, it is possible to perceive a discursive connection between river, governmental interests and the network of sociability that was created around its margins. On the descriptions compiled by the Kellers of the physical and natural spaces on the Iguaçu River, one can find compelling narratives about the riparian peoples and their lifestyles.

Keywords: Iguaçu River. Landscape. Environment. Regional history.

Artigo recebido em 17/08/2011

Artigo aprovado para publicação em 20/04/2012 